\title{
Modeling of Individual and Organizational Factors Affecting Traumatic Occupational Injuries Based on the Structural Equation Modeling: A Case Study in Large Construction Industries
}

\author{
Iraj Mohammadfam, ${ }^{1}$ Ahmad Soltanzadeh,${ }^{1, *}$ Abbas Moghimbeigi, ${ }^{2}$ and Mehdi Akbarzadeh ${ }^{3}$ \\ ${ }^{1}$ Department of Occupational Hygiene Engineering, School of Public Health and Research Center for Health Sciences, Hamadan University of Medical Sciences, Hamadan, IR \\ Iran \\ ${ }^{2}$ Modeling of Non-communicable Disease Research Center, Department of Biostatistics and Epidemiology, School of Public Health, Hamadan University of Medical Sciences, \\ Hamadan, IR Iran \\ ${ }^{3}$ Epidemiology and Biostatistics Department, Public Health Faculty, Hamadan University of Medical Sciences, Hamadan, IR Iran \\ "Corresponding author: Ahmad Soltanzadeh, PhD Candidate, Department of Occupational Hygiene Engineering, School of Public Health and Research Center for Health \\ Sciences, Hamadan University of Medical Sciences, Hamadan, IR Iran. Tel: +98-9120187486, E-mail: Soltanzadeh.ahmad@gmail.com
}

Received 2015 October 04; Revised 2016 January 09; Accepted 2016 January 30.

\begin{abstract}
Background: Individual and organizational factors are the factors influencing traumatic occupational injuries.

Objectives: The aim of the present study was the short path analysis of the severity of occupational injuries based on individual and organizational factors.

Materials and Methods: The present cross-sectional analytical study was implemented on traumatic occupational injuries within a ten-year timeframe in 13 large Iranian construction industries. Modeling and data analysis were done using the structural equation modeling (SEM) approach and the IBM SPSS AMOS statistical software version 22.0, respectively.

Results: The mean age and working experience of the injured workers were $28.03 \pm 5.33$ and $4.53 \pm 3.82$ years, respectively. The portions of construction and installation activities of traumatic occupational injuries were $64.4 \%$ and $18.1 \%$, respectively. The SEM findings showed that the individual, organizational and accident type factors significantly were considered as effective factors on occupational injuries' severity $(\mathrm{P}<0.05)$.

Conclusions: Path analysis of occupational injuries based on the SEM reveals that individual and organizational factors and their indicator variables are very influential on the severity of traumatic occupational injuries. So, these should be considered to reduce occupational accidents' severity in large construction industries.
\end{abstract}

Keywords: Traumatic Occupational Injuries, Structural Equation Modeling, Accident Severity Rate, Individual and Organizational Factors, Construction Industry

\section{Background}

Despite significant progresses to promote occupational safety and health, the statistical rate of traumatic occupational accidents and injuries is reported very high. Traumatic occupational injuries are one of the most negative consequences of severe injuries, which caused by occupational accidents. Furthermore, some studies indicated that these injuries can lead to catastrophic effects on communities, industries, and economy (1-3). International labor organization (ILO) reported that in every 15 second, a worker dies from a work-related accident or disease and 153 workers experience a job-related accident. In addition, 6300 people die as a result of occupational accidents or work-related diseases every day; it is reported that there are more than 2.3 million deaths per year. Also, 317 million accidents occur at work annually; many of them give rise to prolong absences from work. The human cost of this daily adversity is excessive and the economic burden of poor occupational safety and health practices is estimated 4 percent of universal gross domestic product (4).

Construction industry as one of the main industries faced with the challenges of safety and health performance and this is attributed to a large number of traumatic occupational injuries (5-8). Furthermore, within two decades, more than 26,000 workers of construction industry in the United States have died at work, which means five workers' death per day (9). According to statistics, most of the accidents that occur in Iranian construction sites pose severe human injuries (8). Besides, although less than $12 \%$ of Iranian workers are active in the construction industry, statistics have shown that the severity of these injuries is very extreme (10). The most fatal hazards in this 
industry could originate from different sources such as continuous changes in construction projects, using excessive resources, poor working conditions, noncontinuous or cross-seasonal work (6,11-13), manual material handling, outdoor work, direct exposure to outside weather, and environmental pollutants such as noise, vibration, and dust $(6,14,15)$. These often lead to occupational accidents in construction projects such as falling, slipping, collision and crash, chemical exposure, electrical shock, and abrasion $(11,12,16)$.

One of the most important indices of occupational injuries is the severity and consequence of occupational injuries $(17,18)$. The severity of traumatic occupational injuries can be evaluated by using the number of lost working days due to the injuries, some indices such as the accident severity rate (ASR), and the amount of damages to body limbs (19, 20). Severity of occupational injuries is introduced as a dependent-endogenous factor, which may be caused by several exogenous factors and variables (18).

Generally, different factors could have influence on severity of traumatic injuries followed by occupational accidents in the construction industries. Some researchers indicated that individual and organizational factors are considered as the highly influential factors on occupational injuries' severity in construction (21-25). Individual factors (IFs) are attributed to demographic features of injured workers such as age, working experience, education, and marital status $(22,25,26)$; organizational factors are related to workplace factors and features of organization structure such as job title or organizational level, activity type, presence of time pressure for completing activities, use of contractor workforce and others $(24,25,27)$. Furthermore, individual and organizational factors could be considered as a direct, indirect and also a mediator factor, which affected occupational injuries $(8,23)$.

Although some efforts have been put into practice by researchers to determine and analyze the role of individual and organizational factors in occupational injuries, these studies were mostly descriptive, additionally analytical studies only have noted the impact of these factors and variables. Furthermore, they did not mention the portion of any factors and relationship of the variables and the combined effects of individual and organizational factors on traumatic occupational injuries $(6,8,22,25,26$, 28). Structural equation modeling (SEM) is a comprehensive statistical approach and strong analysis technique of multivariable regressions and a comprehensive statistical approach used to testing hypotheses about interrelations of latent and observes variables $(18,29,30)$. The structural equation modeling is capable of recognizing complex relations between different variables, analyzing latent factors, and determining each part of factors/variables in the final event. Also, it could be advantageous in presenting a model for analyzing and predicting accidents' severity. To put it more simply, SEM understands a complex relation between indicator variables as well as endogenous and exogenous latent factors $(18,29,30)$.

\section{Objectives}

Therefore, the present study aimed at analyzing and modeling of traumatic construction injuries based on individual and organizational factors by the use of structural equation modeling in order to find complex relations between different factors such as individual and organizational factors of traumatic occupational injuries, and discover each part of factors in severity of the injuries. Furthermore, it is noteworthy that the purpose of applying structural equation modeling was the path analysis and determination of the impact and role of these factors and their indicator variables on the severity of occupational injuries in construction industry.

\section{Materials and Methods}

This cross-sectional analytical study was conducted on occupational accidents in the 13 large Iranian construction industries within 10 years (2005 to 2014). Furthermore, analyzed data included information about occupational injuries from construction accidents and the accidentrelated individual and organizational factors.

\subsection{Factors and Variables of Study}

Dependent and independent factors and variables of the study respectively included severity of occupational injuries induced by the construction accidents and factors such as individual, organizational and accident type. According to the findings of some SEM studies $(18,29,30)$ as well as the designed algorithm of the study, each of these independent factors were known as an exogenous latent factor, which every of the three factors contained observed indicator variables.

\subsubsection{Dependent Factor}

A studied dependent factor in the present study was the severity of traumatic occupational injuries arisen from the construction accidents. This factor included indicator variables such as ASR, and damaging body limbs. The accident severity rate and damage to body limbs respectively indicate the quantitative and qualitative values of the severity of traumatic occupational injuries. So, to show the importance of the two dependent variables and determine the value of each of these variables, both of the variables were used in the dependent factor. In addition, ASR is 
an index for quantitative analysis and modeling of occupational injuries, and also these indices has been applied to measure safety and health performance and identify safety problems (31). Occupational safety and health administration (OSHA) calculated ASR as follows (32): $A S R$

$=\frac{\text { Total number of lost working days } \times 200000}{\text { Total number of hours worked }}$

\subsubsection{Independent Factors}

As mentioned, the individual, organizational and accident type factors were introduced as independent factors in the study. An individual factor is considered as one of the causal factors of occupational accidents' severity. The IF included some observed indicator variables such as average age, working experience, education, and marital status (22, $25,26,28)$. Also, organizational factor is one of the most important occupational accidents' factors in construction. Indicator variables of organizational factor assessed in the current study included the job title and organizational level, construction activity type, number of workers, time pressure, and contractor $(24,25,27)$. In some occupational safety and health studies, the two factors are together assessed and analyzed $(25,27)$ and sometimes are known as IOF (individual and organizational factors) (23). Therefore, in this study, the impact and the role of these two factors and their indicator variables in the path analysis of traumatic occupational injuries was analyzed. Indicator variables including falling, throwing objects, slipping, crash and collisions, chemicals splurge, contacts with objects or electrical circuit, and accidents arising from manual handling are specified as an exogenous latent accident type factor (ATF), which is the last factor before an accident happens $(13,27)$. It should be noted that the purpose of selecting individual, organizational and accident type factors was to assess and analysis the impact of these factors and their variables on the severity of traumatic injuries in the studied construction industry.

\subsection{Implementation Steps}

According to the designed algorithm for implementation of the study, three steps were taken as follows:

The first step was attributed to collection and verification of data related to construction accidents and calculating the severity of traumatic occupational injuries. In the first step, required data had been collected by investigating accidents' report forms, interviews and checklists. Then, gathered data was revised and those which had missing information were excluded. Finally, 1142 occupational accidents were selected to put into the study. Then, according to traumatic injuries' nature, severity indices including LWD and ASR were calculated.
The second step was related to data gathering about independent factors such as IF, OF, ATF, and their related indicator variables. Information on the latent factors of individual, organizational and accident type factors and the related indicator variables contributed to the occupational injuries was collected and evaluated.

The second step dedicated to modeling the traumatic construction injuries based on the structural equation modeling approach. In this step, the designed conceptual model's basics and all data of the study were entered to the statistical software of IBM SPSS AMOS version 22.0. Afterwards, the relationship modeling of independent factors and variables with dependent variables was done. The SEM approach was selected for this study because it is capable of discovering complex relations between different variables, analyzing latent factors, and determining each part of the factors and variables in the final event. Also, it could be advantageous in presenting a model for analyzing and predicting severity of occupational accidents. To put it more simply, the SEM understands a complex relation between indicator variables as well as endogenous and exogenous factors. In addition, before SEM modeling was done, the designed conceptual model had been verified and approved using the confirmatory factor analysis (CFA). The goodness of fit of this model was evaluated using several indices including $\chi^{2} / \mathrm{df}$, root mean square error of approximation (RMSEA), comparative fit index (CFI), normed-fit index (NFI), and nonnormed fit index (NNFI) or tucker-Lewis index (TLI). For acceptable fit, the range of the ratio $\chi^{2} / \mathrm{df}$, RMSEA, CFI and TLI were 2 - 3, 0.05 - 0.08, 0.95 1.00 and $0.95-1.00$, respectively $(18,29-30)$.

\section{Results}

Table 1 shows the results of occupational injuries' severity. The average of the accident severity rate (ASR) during the 10 -years was $212.80 \pm 122.98$. The results showed that most injuries respectively were related to traumatic shock (48.3\%), multiple lesion (47.4\%), and cutting (46.8\%). Furthermore, an amputation injury rate was estimated $9.8 \%$.

Descriptive findings of independent factors including IF, OF, and ATF can be seen in table 2 . The individual results showed that the mean age and working experience of injured workers were $28.03 \pm 5.33$ and $4.53 \pm 3.82$ years, respectively. Almost 70\% of injured workers had no academic education, and the number of married or single one was the same. The organization findings showed that over $70 \%$ of the injured staffs were simple constructional workers and about $25 \%$ of them were technicians. Constructional work included the high frequency of accidents (twothird); $18.1 \%$ of occupational accidents occurred in installa- 
Table 1. Severity of Occupational Injuries

\begin{tabular}{|cc|}
\hline Accidents Index & Value and Frequency \\
\hline ASR $(\mathbf{M} \pm \mathbf{S D})$ & $212.80 \pm 122.98$ \\
\hline Accident nature & \\
\hline Amputation & $112(9.8 \%)$ \\
\hline Internal injury & $445(39.0 \%)$ \\
\hline Traumatic shock & $552(48.3 \%)$ \\
\hline Burn & $139(12.2 \%)$ \\
\hline Multiple lesion & $541(47.4 \%)$ \\
\hline Cutting & $525(46.8 \%)$ \\
\hline
\end{tabular}

tion activities. Furthermore, contractors were contributed to $72.7 \%$ of traumatic injuries, and $70.6 \%$ of the injuries was resulted from time pressure. Also, the findings of accident type factor showed that most of the accidents were attributed to falling from height (30.6\%), collision (30.5\%), stuck in/on objects (29.9\%), and struck by falling objects (26.9\%).

The findings of modeling of traumatic construction injuries based on the SEM approach were illustrated in Figure 1. The results showed the significant relationship between factors like IF, OF, and ATF and their indicator variables $(\mathrm{P}<0.05)$. Also, a significant relationship was found between the dependent factor (traumatic injuries) and its variables $(\mathrm{P}<0.05)$. Moreover, the result of the SEM analysis represented positive and negative effects of each variables/factors on traumatic injuries. Furthermore, the analysis of goodness of fit of the preferred conceptual model showed that the value of indices such as $\chi^{2} / \mathrm{df}$, RMSEA, CFI and NNFI were 3.08, 0.063, 0.970, and 0.955, respectively. Therefore, this model was acceptable according to the results of goodness of fit.

Referring to the Figure 1, the value of estimated parameters placed in the arrows and numbers within the parentheses represented standard error (SE) and T-value, respectively. So, the SEM results showed that the most effective variables on IF was respectively related to indicator variables such as age (estimated parameter $=4.81$ ), working experience (1.31), education (1.0), and marital status (0.672). Indicator variables including activity type (2.21), number of workers in each project (1.68), use of contractor workers (1.0), job title (0.638), and time pressure (0.284) mostly affected the organization factor (OF). Moreover, the impacts of falling from height (6.63), struck by falling object (4.80), and stuck in/on objects (1.28) were more effective than collision (1.0), electrocution (0.645), and chemical spillage (0.324) on accident type factor (ATF). Analysis of the traumatic injuries as dependent factor revealed that accident
Table 2. Descriptive Analysis of Individual Factors, Organizational Factors and Accident Type Factors

\begin{tabular}{|c|c|}
\hline Indicator Variables & Descriptive Values \\
\hline \multicolumn{2}{|c|}{ Individual Factors (IFs) } \\
\hline Age, $y(m \pm S D)$ & $28.03 \pm 5.33$ \\
\hline Job experience $(\mathrm{m} \pm \mathrm{SD})$ & $4.53 \pm 3.82$ \\
\hline \multicolumn{2}{|l|}{ Education } \\
\hline Under diploma & $367(32.1 \%)$ \\
\hline Diploma & $450(39.4 \%)$ \\
\hline Academic degree & $325(28.5 \%)$ \\
\hline \multicolumn{2}{|l|}{ Marital status } \\
\hline Single & $571(50.0 \%)$ \\
\hline Married & $571(50.0 \%)$ \\
\hline \multicolumn{2}{|c|}{ Organizational Factors (OFs) } \\
\hline No. Workers average $(\mathrm{m} \pm \mathrm{SD})$ & $40.11 \pm 23.25$ \\
\hline \multicolumn{2}{|l|}{ Job title } \\
\hline Simple workers & $813(71.2 \%)$ \\
\hline Technicians & $291(25.5 \%)$ \\
\hline Supervisor & $38(3.3 \%)$ \\
\hline \multicolumn{2}{|l|}{ Activity type } \\
\hline Construction & $735(64.4 \%)$ \\
\hline Installation & $207(18.1 \%)$ \\
\hline Manual handling & $110(9.6 \%)$ \\
\hline Maintenance & $90(7.9 \%)$ \\
\hline Contractor & $830(72.7 \%)$ \\
\hline Time pressure & $806(70.6 \%)$ \\
\hline \multicolumn{2}{|c|}{ Accident Type Factors (ATFs) } \\
\hline Fall & $350(30.6 \%)$ \\
\hline Struck by falling object & $307(26.9 \%)$ \\
\hline Caught in/or between objects & $342(29.9 \%)$ \\
\hline Collision & $348(30.5 \%)$ \\
\hline Electrocution & $109(9.5 \%)$ \\
\hline Chemical spilling & $100(8.8 \%)$ \\
\hline
\end{tabular}

severity rate (1.68)and injury's nature (1.0) were considered as variables of the occupational traumatic injuries in the construction industries.

Based on the findings of structural equation modeling, the effects of individual and organizational factors on the accident type factor were reported significantly negative (respectively-3.43 and-0.683). The final result of this model was the relationship between ATF and the traumatic injury factor. The effect of accident type factor on injury factor was estimated 2.21. Hence, according to other results of 


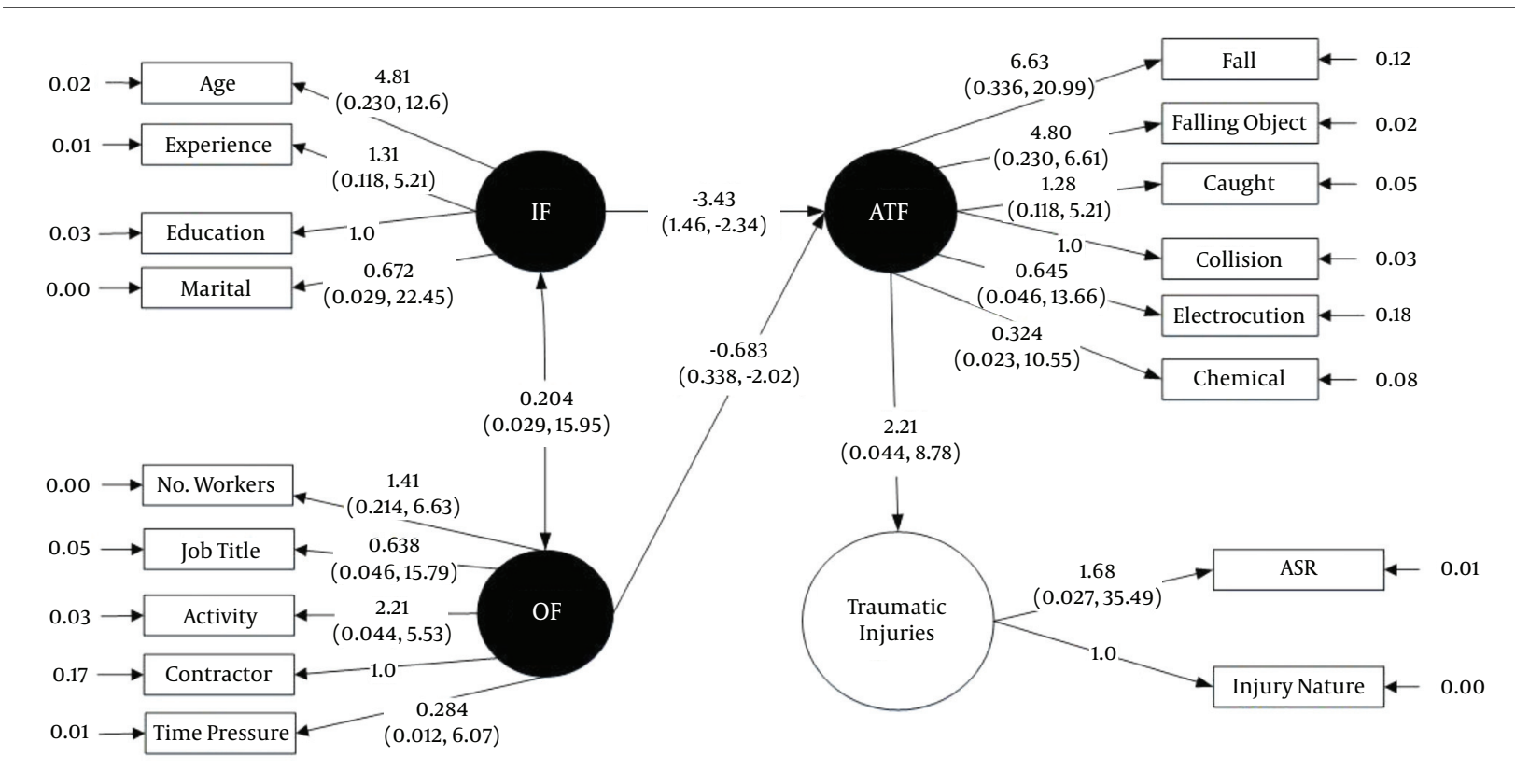

Figure 1. Structural Equation Model of Occupational Traumatic Injuries

SEM, the more the factors like IF, OF, and their indicator variables increase, the less ASR and injury we will have.

\section{Discussion}

The present study which aimed at modeling of traumatic construction injuries on the basis of individual and organizational factors implied that individual, organizational, and factors related to accident occurrence in construction are the important factors affecting ASR. In addition, both descriptive and analytical results of the present study revealed that the traumatic occupational injuries are very severe, which this finding is consistent with other studies (21-25).

Path analysis of traumatic occupational injuries based on IF, OF, and ATF showed that these factors and their indicator variables were significantly related to construction ASR. The SEM results indicated that IF and OF had a negative significant relationship with ATF. In other words, the more individual and organizational factors increase, the more the accident type factor decrease. Also, the relationship between ATF and ASR was significantly positive. In other words, the more ATF increase, the more the occupational traumatic injuries were improved (24-25, 28).

The SEM findings indicated that some variable related to IF including mean age, working experience, education, and marital status, additionally OF's indicator variables such as the activity type, number of workers in each project, use of contract workers, job title, organizational level, and time pressure were explored and determined as significant related factors to ASR in the 13 large construction industries. Consistent with these results, some researchers have reported that individual and organizational factors mostly affected occupational accidents' severity $(21,22)$. Individual and organizational factors play direct and mediator roles in ASR (23).

The individual and demographic factors are considered as one of the causal factors of occupational injuries $(23,28)$. In addition to their direct effects, some studies showed that some indicator variables of IF such as age and working experience played an important role as a mediating factor in occupational accidents' severity $(22,23)$. Furthermore, job or activity type is a significant causal factor affects injuries' severity directly or even while interacting with other factors (23-25).

Organizational factor is known as one of the most important factors in accidents analysis. Organization and management structure features are important accident variables which can produce problems in the process of safe implementation of work or affect occupational accidents while are being in contact with underlying factors $(23,25)$. The researchers have implied that some indicator variables of $\mathrm{OF}$ in construction industries including construction activity type, number of workers, contractors, and time pressure played an important role in occurrence and severity of occupational accidents and injuries. The 
role of organization is in the processes including training, work procedures and instructions, monitoring, and leadership. Therefore, OF sometimes is considered as a root cause of accidents and their consequences $(24,25,27)$.

The accident type factor and its related indicator variables directly affect severity of construction accidents; in other words, in the circle of factors which lead to accident happening, ATF sits in the last seat. Thus, they are so important to severity of traumatic occupational injuries. In this study, the indicator variables of latent ATF included falling from height, struck by falling object, stuck in/on objects, collision, electrocution, and chemical spillage $(8,13,33)$.

Finally, despite all limitations of data gathering, the numbers of analyzed variables were almost sufficient. Other limitations of this study included the long-lasting process of data gathering as well as a-large-scale geographical distribution of the studied workplaces. Furthermore, authors suggest that the SEM approach could be introduced to H\&S engineers as a common method for analysis and modeling of the occupational injuries.

Furthermore, we propose that a study to be designed and performed for the path analysis of construction injuries based on the SEM approach according to all factors and variables such as individual, organizational, HSE training and risk management, unsafe conditions and unsafe acts for the future.

\subsection{Conclusion}

The results of the present study show that path analysis with applying the SEM approach is a good way in analyzing the severity of traumatic occupational injuries. The SEM findings conclusively reveal that the indicator variables of individual and organizational factors indirectly and variables of accident type factor directly are related to severity of occupational injuries in the construction industries. So, these factors and variables should be noticed to reduce traumatic occupational injuries in large construction industries and should be applied in the design and implementation of management systems related to HSE.

\section{Acknowledgments}

This paper was extracted from the PhD dissertation in occupational health engineering. We would like to thank the research center for health sciences, Hamadan University of Medical Sciences, for its partially financial support. The authors wish to sincerely thank Mr. Shahram Mahmoudi and HSE engineers of the 13 large construction industries for their invaluable and skillful assistance in data gathering in the studied construction sites.

\section{Footnote}

Authors' Contribution: The concept and design of the study was for Iraj Mohammadfam and Ahmad Soltanzadeh; Ahmad Soltanzadeh undertook the literature search, collected the data; Ahmad Soltanzadeh and Abbas Moghimbeigi and Mehdi Akbarzadeh analyzed data and synthesized the results; Ahmad Soltanzadeh and Iraj Mohammadfam drafted the manuscript; Abbas Moghimbeigi and Mehdi Akbarzadeh contributed to themes analysis and reviewed the draft manuscript; All authors contributed significantly to revisions and approved the final manuscript.

\section{References}

1. Gholipour C, Shams Vahdati S, Ghaffarzade E, Kashi Zonouzy K. Characteristics of Fatal Occupational Traumatic Injuries; Drama in East Azerbaijan Province of Iran. Bull Emerg Trauma. 2015;3(1):27-31. [PubMed: 27162897].

2. Souza K, Cantley LF, Slade MD, Eisen EA, Christiani D, Cullen MR. Individual-level and plant-level predictors of acute, traumatic occupational injuries in a manufacturing cohort. Occup Environ Med. 2014;71(7):477-83. doi: 10.1136/oemed-2013-101827. [PubMed: 24727737].

3. Honarpisheh H. A comprehensive model for trauma research design. Arch Trauma Res. 2012;1(1):3-13. doi: 10.5812/atr.5288. [PubMed: 24719834].

4. ILO . Statistics of occupational accidents and imjuries Safety and Health Topic; 2015. Available from: http://www.ilo.org/global/topics/ safety-and-health-at-work/lang--en/index.htm.

5. Colak B, Etiler N, Bicer U. Fatal occupational injuries in the construction sector in Kocaeli, Turkey, 1990-2001. Ind Health. 2004;42(4):42430. [PubMed: 15540625].

6. Im HJ, Kwon YJ, Kim SG, Kim YK, Ju YS, Lee HP. The characteristics of fatal occupational injuries in korea's construction industry, 1997-2004. Safety Science. 2009;47(8):1159-62.

7. Manu P, Ankrah N, Proverbs D, Suresh S. An approach for determining the extent of contribution of construction project features to accident causation. Safety Science. 2010;48(6):687-92. doi: 10.1016/j.ssci.2010.03.001.

8. Soltanzadeh A, Mohammadfam I, Akbarzadeh M. Studying disabling occupational accidents in the construction industry during two years. J Occupation Hygiene Engineer. 2014;1(2):57-66.

9. Hinze JW, Teizer J. Visibility-related fatalities related to construction equipment. Safety Science. 2011;49(5):709-18. doi: 10.1016/j.ssci.2011.01.007.

10. Moradinazar M, Kurd N, Farhadi R, Amee V, Najafi F. Epidemiology of work-related injuries among construction workers of ilam (Western iran) during 2006 - 2009. Iran Red Crescent Med J. 2013;15(10):8011. doi: 10.5812/ircmj.8011. [PubMed: 24693372].

11. Brace C, Gibb AGF, Pendlebury M, Bust PD. Health and safety in the construction industry: Underlying causes in construction fatal accidents-external research. HSE Report. 2009:205.

12. Cameron I, Hare B, Davies R. Fatal and major construction accidents: A comparison between scotland and the rest of great britain. Safety Science. 2008;46(4):692-708. doi:10.1016/j.ssci.2007.06.007.

13. Cheng CW, Leu SS, Lin CC, Fan C. Characteristic analysis of occupational accidents at small construction enterprises. Safety Science. 2010;48(6):698-707. doi: 10.1016/j.ssci.2010.02.001.

14. Tam CM, Zeng SX, Deng ZM. Identifying elements of poor construction safety management in china. Safety Science. 2004;42(7):569-86. doi:10.1016/j.ssci.2003.09.001. 
15. Pinto A, Nunes IL, Ribeiro RA. Occupational risk assessment in construction industry - overview and reflection. Safety Science. 2011;49(5):616-24. doi:10.1016/j.ssci.2011.01.003.

16. Grant A, Hinze J. Construction worker fatalities related to trusses: An analysis of the osha fatality and catastrophic incident database. Safety Science. 2014;65:54-62. doi:10.1016/j.ssci.2013.12.016.

17. Mohammadfam I, Soltanzadeh A, Moghimbeigi A, Savareh BA. Use of Artificial Neural Networks (ANNs) for the Analysis and Modeling of Factors That Affect Occupational Injuries in Large Construction Industries. Electron Physician. 2015;7(7):1515-22. doi:10.19082/1515. [PubMed: 26767107].

18. Lee JY, Chung JH, Son B. Analysis of traffic accident size for Korean highway using structural equation models. Accid Anal Prev. 2008;40(6):1955-63. doi: 10.1016/j.aap.2008.08.006. [PubMed: 19068300].

19. Feng Y, Teo EAL, Ling FYY, Low SP. Exploring the interactive effects of safety investments, safety culture and project hazard on safety performance: An empirical analysis. Inter J Proj Manage. 2014;32(6):932-43. doi: 10.1016/j.ijproman.2013.10.016.

20. Onder M, Onder S, Adiguzel E. Applying hierarchical loglinear models to nonfatal underground coal mine accidents for safety management. Int J Occup Saf Ergon. 2014;20(2):239-48. doi: 10.1080/10803548.2014.11077052. [PubMed: 24934420].

21. Sawacha E, Naoum S, Fong D. Factors affecting safety performance on construction sites. Inter J Proj Manage. 1999;17(5):309-15. doi 10.1016/s0263-7863(98)00042-8.

22. Salminen S. Have young workers more injuries than older ones? An international literature review. J Safety Res. 2004;35(5):513-21. doi 10.1016/j.jsr.2004.08.005. [PubMed: 15530925].

23. Oliver A, Cheyne A, Tomas JM, Cox S. The effects of organizational and individual factors on occupational accidents. J Occupation Organ Psychol. 2002;75(4):473-88. doi:10.1348/096317902321119691.

24. Mearns K, Rundmo T, Flin R, Gordon R, Fleming M. Evaluation of psychosocial and organizational factors in offshore safety: A comparative study. J Risk Rese. 2004;7(5):545-61. doi: $10.1080 / 1366987042000146193$.

25. Haslam RA, Hide SA, Gibb AG, Gyi DE, Pavitt T, Atkinson S, et al. Contributing factors in construction accidents. Appl Ergon. 2005;36(4):401-15. doi: 10.1016/j.apergo.2004.12.002. [PubMed: 15892935].

26. Chi CF, Chang TC, Ting HI. Accident patterns and prevention measures for fatal occupational falls in the construction industry. Appl Ergon. 2005;36(4):391-400. doi: 10.1016/j.apergo.2004.09.011. [PubMed: 15892934].

27. Abdelhamid TS, Everett JG. Identifying root causes of construction accidents. J Construct Engineer Manag. 2000;126(1):52-60. doi: 10.1061/(asce)0733-9364(2000)126:1(52).

28. Fazel MR, Fakharian E, Mahdian M, Mohammadzadeh M, Salehfard L, Ramezani M. Demographic Profiles of Adult Trauma During a 5 Year Period (2007-2011) in Kashan, IR Iran. Arch Trauma Res. 2012;1(2):63-6. doi: 10.5812/atr.6770. [PubMed: 24396745].

29. Martínez CM, Gracia F, Tomás I, Peiró JM. Leadership and employees' perceived safety behaviours in a nuclear power plant: A structural equation model. Safety Science. 2011;49(8-9):1118-29. doi: 10.1016/j.ssci.2011.03.002.

30. Chen H, Qi H, Wang O, Long RY. Research on structural equation model of affecting factors of deliberate violation in coalmine fatal accidents in china. Systems Engineering -Theory and Practice. 2007;27(8):127-36. doi:10.1016/s1874-8651(08)60050-2.

31. Sari M, Selcuk AS, Karpuz C, Duzgun HSB. Stochastic modeling of accident risks associated with an underground coal mine in turkey. Safety Science. 2009;47(1):78-87. doi:10.1016/j.ssci.2007.12.004

32. Safety OSHA. Health management systems etool. Hazard Prevention and Control. http://www. osha. gov/SLTC/etools/safetyhealth/comp3. html. Accessed September. 2012;7.

33. Mahdian M. Fall injuries: an important preventable cause of trauma. Arch Trauma Res. 2013;2(3):101-2. doi: 10.5812/atr.16079. [PubMed: 24693517]. 